\title{
Anatomical Pattern of Dorsal Metatarsal Arteries in a Black Kenyan Population
}

\author{
Thomas Amuti $^{10}$ Lee Oyugi ${ }^{1}$ Innocent Ouko ${ }^{1}$ Ibsen Ongidi ${ }^{1}$ Julius Ogeng'o ${ }^{1}$ \\ ${ }^{1}$ Department of Human Anatomy, University of Nairobi, University of
Nairobi, Nairobi, Kenya \\ J Morphol Sci 2019;36:169-173. \\ Address for correspondence Thomas Amuti, BSc, Department of \\ Human Anatomy, University of Nairobi, 30197-00100, Nairobi, Kenya \\ (e-mail: tomamuti@gmail.com).
}

\begin{abstract}
Keywords

- dorsal metatarsal arteries

- interossei muscles

- dorsal myocutaneous flaps

- foot

- dorsalis pedis

Introduction Knowledge of anatomical variations in the origin and in the course of the dorsal metatarsal arteries (DMTAs) is valuable for many procedures, including reconstructive surgeries and flap selection. However, there is a paucity of data on these arteries among black Africans.

Materials and Methods The present study studied the origin and the location of DMTAs in 30 formalin-fixed cadaveric feet of adult black Kenyans at the Department of Human Anatomy of the University of Nairobi, Nairobi, Kenya.

Results Dorsal metatarsal arteries were present in all of the cases. Of the right dorsalis pedis artery (DPA), in the majority of the cases, the $1^{\text {st }}$ DMTA arose as the continuation of the DPA, while the $2^{\text {nd }}$ to $4^{\text {th }}$ DMTAs were given off as branches from the arcuate artery (AA). On the left feet, in the majority of the cases, the $1^{\text {st }}$ DMTA arose as the continuation of the DPA, while the rest were given off as branches from the AA. In relation to the dorsal interossei muscles, all of the the arteries were either within the muscle fibers $(53 \%)$ or beneath them $(47 \%)$, on the right side. On the left side, the $1^{\text {st }}$ DMTA was above the muscles in $40 \%$ of the cases; within the muscles in $53 \%$; and beneath the muscles in $7 \%$. The $2^{\text {nd }}$ and $3^{\text {rd }}$ DMTAs were above the muscles in $57 \%$ and in $53 \%$ of the cases, respectively.

Conclusion These results reveal that the DMTAs show variation in their origin and position relative to the dorsal interossei muscles. These variations display bilateral asymmetry.
\end{abstract}

\section{Introduction}

The dorsal metatarsal arteries (DMTAs) are the main blood supply to the structures located dorsally between the digits. They course between the metatarsal bones to bifurcate at the web of the toes into the proper dorsal digital arteries. Normally, the $1^{\text {st }}$ DMTA is a branch of the dorsalis pedis artery (DPA), given off before the deep plantar artery and the arcuate artery (AA). The other DMTAs arise as branches from the AA, which is a branch of the DPA. ${ }^{1,2}$

Variations have been reported on the origin of these vessels, as well as on their course between the web spaces. ${ }^{3-9}$

(1)Thomas Amuti's ORCID is https://orcid.org/0000-0003-0532-3653.

received

October 12, 2018

accepted

April 14, 2019
DOI https://doi.org/

10.1055/s-0039-1691757. ISSN 2177-0298.
Knowledge of anatomical variations in the origin and in the course of the DMTAs is valuable to endovascular surgeons when selecting the artery to be revascularized based on the angiosome concept in critical limb ischemia cases in order to avoid amputation of feet of diabetic patients. It is also important in reconstructive surgeries and in flap selection in order to select the vascularized bone graft for reconstruction of metatarsals and digits of the amputated limb and for the reconstruction of the eyelids and of the nasal tip. ${ }^{4}$ There is a paucity of data on these arteries among black Africans. Therefore, the present study aimed to investigate the anatomical variations in the DMTAs in a select Kenyan population.

Copyright @ 2019 by Thieme Revinter Publicações Ltda, Rio de Janeiro, Brazil

\section{License terms}

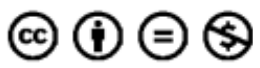




\section{Methods and Materials}

The present study, a descriptive cross-sectional study with a sample size of 30 specimens, was performed at the Department of Human Anatomy of the University of Nairobi, Nairobi, Kenya. The formalin-fixed specimens used were of adults of Kenyan indigenous ethnicity.

To dissect out the DMTA, the skin, the fat, and the fascia of the dorsum of the feet were removed. This exposed the DPA and its branches. The AA was then identified as the artery that branched from the tarsalmetatarsal joint and arched in a semicircular manner beneath the tendons of the extensor hallucis brevis muscle. The extensor digitorum brevis was therefore retracted to allow access to the branches of the AA.

The $1^{\text {st }}$ DMTA was identified as the branch of the dorsalis pedis artery given off before the deep plantar artery and the AA. The other DMTAs were identified as the arteries that branched from the AA and coursed between the metatarsal bones to bifurcate at the web of the toes into the proper dorsal digital arteries. These vessels were then cleaned and tagged for visibility.

The origins of the arteries were then measured from the base of the respective metatarsal bones and recorded. The variations of the origin of the DMTAs, as well as their courses, were also observed and noted. Data was recorded and variations were photographed with a 12.1 megapixels digital camera Carl Zeiss Ikon (Carl Zeiss, Oberkochen, Germany).

The data was coded into SPSS version 21, IBM, in which the means of the different data were calculated. Side variations were also analyzed using the paired t-test. A p-value $\leq 0.05$ was considered significant at a $95 \%$ confidence interval (CI). Data were presented using tables and photographs.

\section{Results}

All of the the DMTAs were present.

\section{Origin of the Dorsal Metatarsal Arteries}

There were different topographical as well as morphometric points of origin as measured from the bases of the respective metatarsal bones.

\section{Topographical Origins of the Dorsal Metatarsal Arteries}

In $33 \%$ of the right DPAs, the $1^{\text {st }}$ DMTA arose as a branch of the DPA, while the rest were given off as branches from the AA. In $20 \%$ of the right DPAs, the $1^{\text {st }}$ DMTA arose as the continuation of the medial dorsalis pedis branch, while the rest were given off by the lateral dorsalis pedis branch. In the remaining $47 \%$ of the right DPAs, the main DPA gave off the $1^{\text {st }}$ DMTA, the $2^{\text {nd }}$ DMTA was given off as a direct branch from the DPA, while the $3^{\text {rd }}$ and $4^{\text {th }}$ DMTAs arose as branches from the lateral tarsal artery (LTA).

In $47 \%$ of the left feet, the $1^{\text {st }}$ DMTA arose as a branch of the DPA, while the rest were given off as branches from the AA. In $13 \%$ of the cases, the $1^{\text {st }}$ DMTA arose as the continuation of the medial dorsalis pedis branch, while the rest were given off by the lateral dorsalis pedis branch. In $40 \%$ of the cases, the $1^{\text {st }}$ DMTA arose as a branch of the DPA, the $2^{\text {nd }}$ DMTA was given off as a direct branch from the DPA, while the $3^{\text {rd }}$ and $4^{\text {th }}$ DMTAs arose as branches from the LTA. (-Figs. 1-3)

\section{Morphometric Origin of the Dorsal Metatarsal Arteries as Measured from the Respective Metatarsal Bases}

The mean distance of the $1^{\text {st }}$ DMTA on the right side arose at a point $2.36 \mathrm{~mm}$ from the base of the $1^{\text {st }}$ metatarsal bone. The mean distance of the $2^{\text {nd }}, 3^{\text {rd }}$ and $4^{\text {th }}$ DMTAs arose at $1.18 \mathrm{~mm}, 1.52 \mathrm{~mm}$, and $1.46 \mathrm{~mm}$ from their respective metatarsal bases, respectively. On the left side, the mean distance of the $1^{\text {st }}$ DMTA arose at a point $1.46 \mathrm{~mm}$ from the base of the $1^{\text {st }}$ metatarsal bone. The mean distance of the $2^{\text {nd }}, 3^{\text {rd }}$ and $4^{\text {th }}$ DMTAs arose at $2.60 \mathrm{~mm}, 1.60 \mathrm{~mm}$ and $1.60 \mathrm{~mm}$ from their respective metatarsal bases, respectively (-Table $\mathbf{1}$ ).

\section{Relation of the Dorsal Metatarsal Arteries to the Dorsal Interossei Muscles}

On the right feet, all of the DMTAs were noted to lie either within the muscle fibers of the dorsal interossei muscles or beneath them. The vessels lay within the muscles in $53 \%$ of the cases, and beneath the muscles in $47 \%$. However, on the left feet, the relation of the DMTAs to the dorsal interossei muscles varied. The $1^{\text {st }}$ DMTA was noted to be above the muscles in $40 \%$ of the cases, within the muscles in $53 \%$, and beneath the muscles in $7 \%$. The $2^{\text {nd }}$ DMTA was noted to be

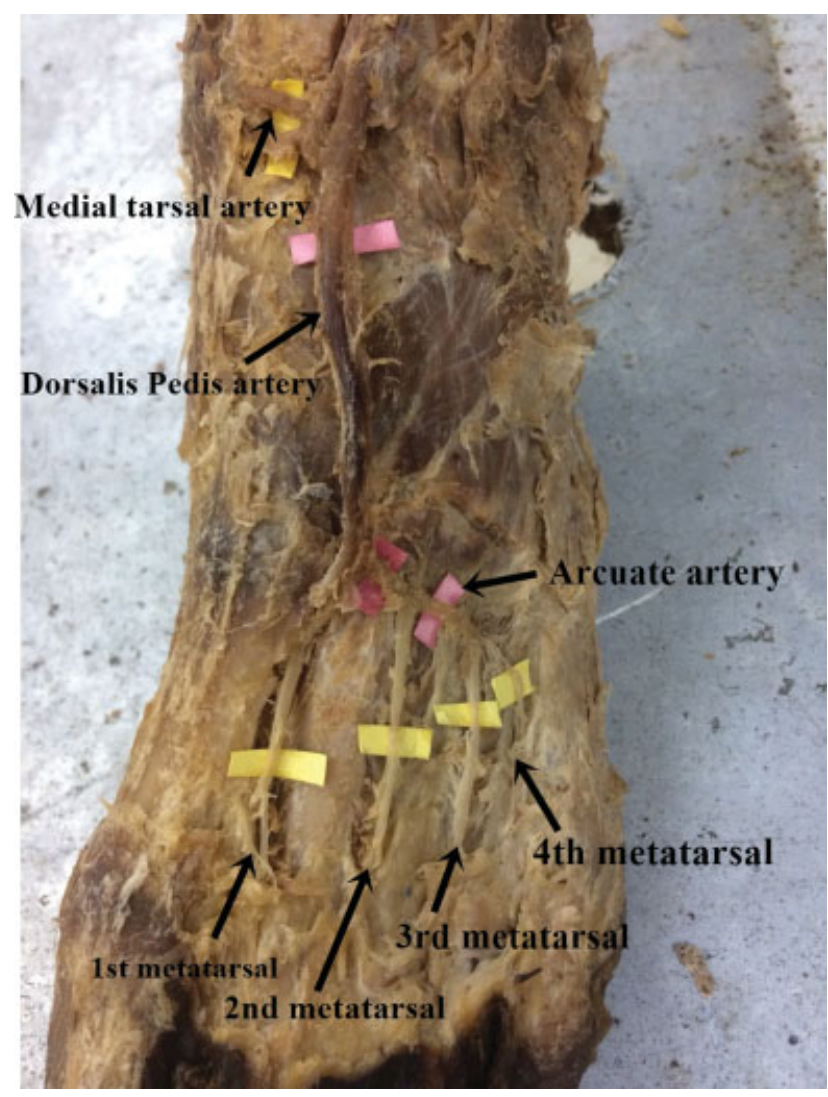

Fig. 1 Image showing the 1st type of branching pattern of the dorsalis pedis artery. Note the dorsalis pedis artery giving the arcuate artery artery (which gives the $2^{\text {nd }}$ to $4^{\text {th }}$ dorsal metatarsal arteries), while the dorsalis pedis artery continues as the $1^{\text {st }}$ dorsal metatarsal artery. 


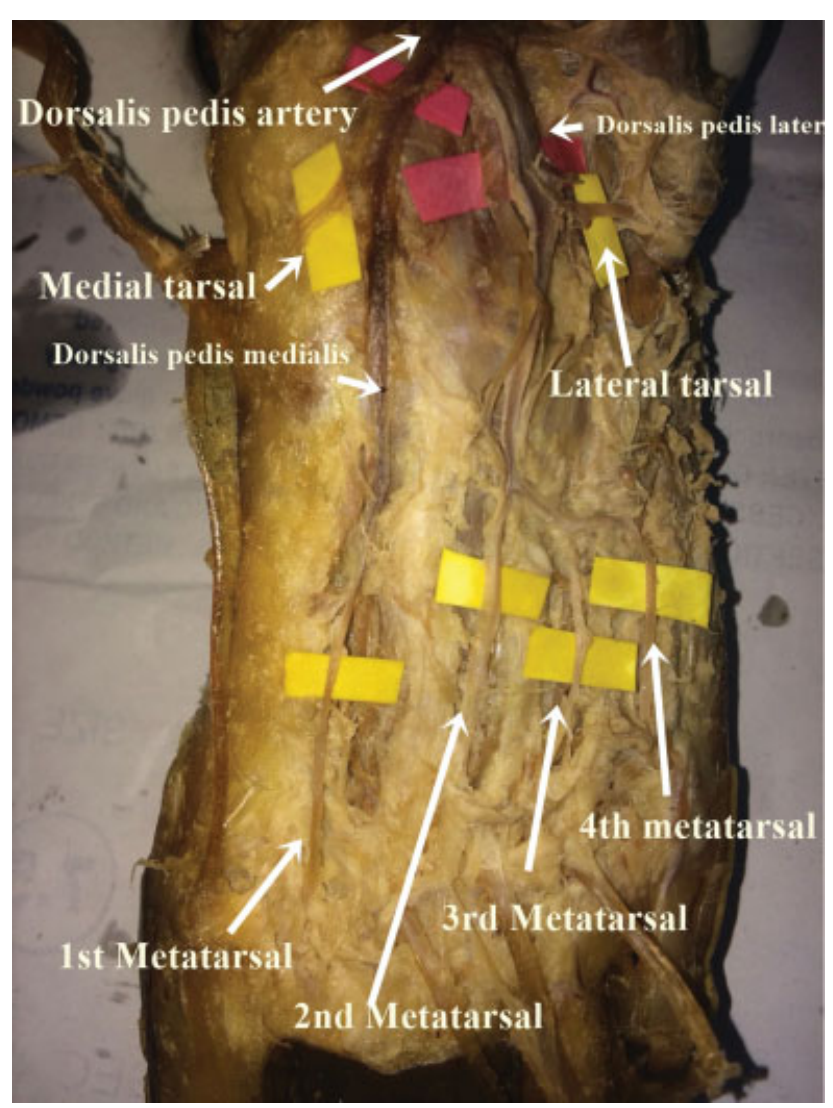

Fig. 2 Image showing the $2^{\text {nd }}$ type of branching pattern of the dorsalis pedis artery. Note the dorsalis pedis artery dividing to give a lateral dorsalis pedis artery and a medial dorsalis pedis artery. The lateral dorsalis pedis artery gives the $2^{\text {nd }}$ to $4^{\text {th }}$ dorsal metatarsal arteries, while the medial dorsalis pedis artery continues as the $1^{\text {st }}$ dorsal metatarsal artery.

above the muscles in $57 \%$ of the cases, and within muscles in $43 \%$. The $3^{\text {rd }}$ DMTA. On the other hand, it was above the muscles in $53 \%$ of the cases, and within the muscles in $47 \%$. The $4^{\text {th }}$ DMTA was noted to be above the muscles also in 53\% of the cases, and within in 47\% (- Table 2) (-Fig. 4A-BC).

\section{Discussion}

All of the the DMTAs were present in all of the cases of the present study. This is similar to data derived by Yeo et $\mathrm{al}^{7}$ in the Singapore population, who found that the $1^{\text {st }}$ DMTA was present in $100 \%$ of the specimens. However, in contrast, in the American population, Upton ${ }^{6}$ found that the $1^{\text {st }}$ DMTA was absent in $9 \%$ of the cases, while Kulkarni et $\mathrm{al}^{5}$ found that the $1^{\text {st }}$ DMTA was absent in $33.3 \%$ of the cases in the Indian population. In another Indian study, Awari et $\mathrm{al}^{3}$ found that the $1^{\text {st }}$ DMTA was absent in $8 \%$ of the feet. Absence of the DMTA could be attributed to some combinations of persistent primitive arterial segments, to abnormal fusions, to segmental hypoplasia of arteries, or to absence during the embryological development. ${ }^{11}$ The presence or absence of DMTAs could influence their selection for flaps; ${ }^{12,13}$ however, since all of the DMTAs were present in our study, their selection in flap and reconstructive surgeries is recommended.

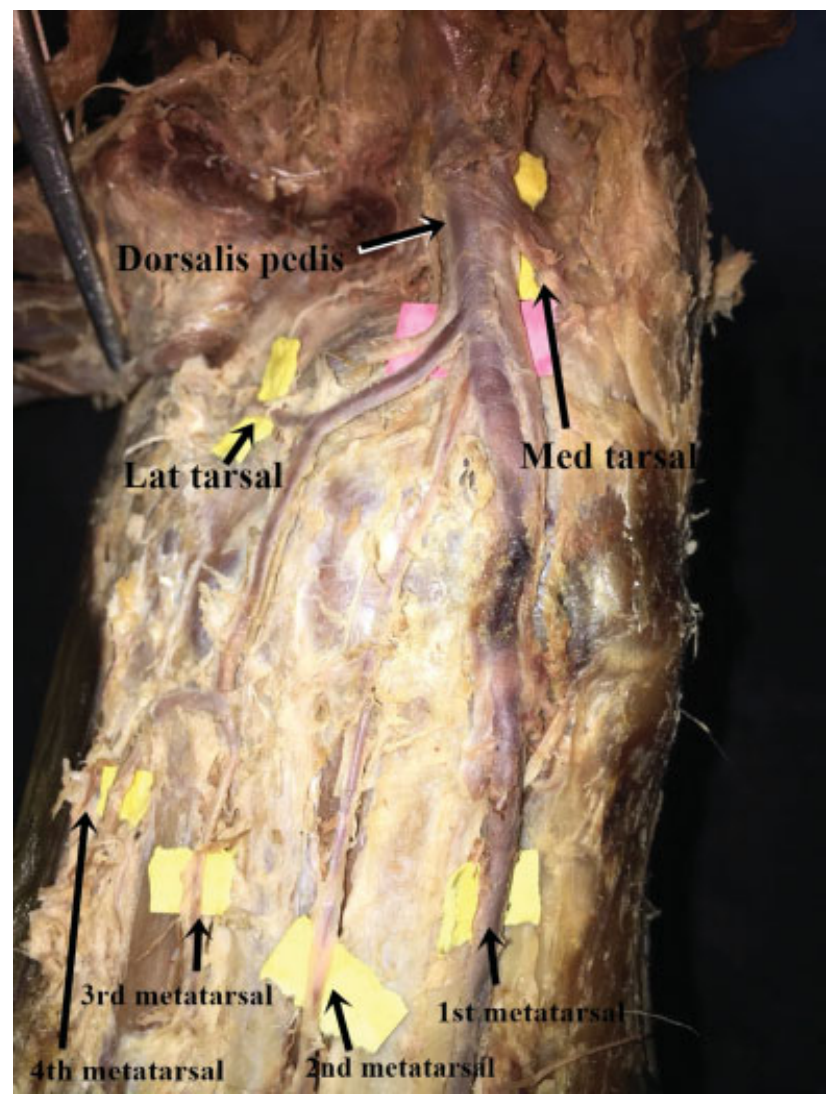

Fig. 3 Image showing the $3^{\text {rd }}$ type of branching pattern of the dorsalis pedis artery. Note that the dorsalis pedis artery gives out the $2^{\text {nd }}$ dorsal metatarsal arteryas a single branch, and the lateral tarsal artery (which gives out the $3^{\text {rd }}$ and $4^{\text {th }}$ dorsal metatarsal arteries). It then continues off as the $1^{\text {st }}$ dorsal metatarsal artery.

Table 1 Morphometric distance of the dorsal metatarsal arteries from their respective metatarsal bone bases

\begin{tabular}{|l|l|l|l|}
\hline Side & Number & \multicolumn{2}{|l|}{$\begin{array}{l}\text { Morphometric distance } \\
(\mathrm{mm})\end{array}$} \\
\hline & & Mean & Range \\
\hline Right & $1^{\text {st }}$ & 2.36 & $0.55-.44$ \\
\hline & $2^{\text {nd }}$ & 1.18 & $1.01-2.82$ \\
\hline & $3^{\text {rd }}$ & 1.52 & $0.84-2.71$ \\
\hline & $4^{\text {th }}$ & 1.46 & $0.84-3.02$ \\
\hline Left & $1^{\text {st }}$ & 1.46 & $0.57-3.83$ \\
\hline & $2^{\text {nd }}$ & 2.60 & $0.65-2.70$ \\
\hline & $3^{\text {rd }}$ & 1.60 & $0.60-2.84$ \\
\hline & $4^{\text {th }}$ & 1.80 & $0.60-2.62$ \\
\hline
\end{tabular}

Regarding the origin of the DMTAs on the right feet, the $1^{\text {st }}$ DMAT originated mostly as a branch of the main DPA, while the $2^{\text {nd }}$ DMTA was given off as a direct branch from the DPA, while the $3^{\text {rd }}$ and $4^{\text {th }}$ DMTAS arose as branches from the LTA. On the left feet, however, the $1^{\text {st }}$ DMTA originated mostly as a branch of the main DPA, while the $2^{\text {nd }}, 3^{\text {rd }}$ and $4^{\text {th }}$ DMTAs arose as branches from the AA. These findings on the origin of the $1^{\text {st }}$ DMTA are similar to those in the Indian population, 
Table 2 Relation of the dorsal metatarsal arteries to the dorsal interossei muscles

\begin{tabular}{|c|c|c|}
\hline Side $(n=30)$ & $\begin{array}{l}\text { Relation of the } \\
\text { DMTA to the dorsal } \\
\text { interossei muscles }\end{array}$ & $\begin{array}{l}\text { Frequency } \\
\text { (\%) }\end{array}$ \\
\hline \multirow{3}{*}{$\begin{array}{l}\text { Right (All DMTAs had } \\
\text { the same pattern) }\end{array}$} & Above & - \\
\hline & Within & 53 \\
\hline & Beneath & 47 \\
\hline \multicolumn{3}{|l|}{ Left } \\
\hline \multirow[t]{3}{*}{$1^{\text {st }}$} & Above & 40 \\
\hline & Within & 53 \\
\hline & Beneath & 7 \\
\hline \multirow[t]{3}{*}{$2^{\text {nd }}$} & Above & 57 \\
\hline & Within & 43 \\
\hline & Beneath & - \\
\hline \multirow[t]{3}{*}{$3^{\text {rd }}$} & Above & 57 \\
\hline & Within & 43 \\
\hline & Beneath & - \\
\hline \multirow[t]{3}{*}{$4^{\text {th }}$} & Above & 57 \\
\hline & Within & 43 \\
\hline & Beneath & - \\
\hline
\end{tabular}

in whom the $1^{\text {st }}$ DMTA was a branch of the DPA in most of the cases. $^{3}$

Regarding the origin of the other DMTAs, data from Egypt found that the $2^{\text {nd }}, 3^{\text {rd }}$, and $4^{\text {th }}$ DMTAs arose from the AA in $85 \%$ of the specimens. ${ }^{8}$ In the Indian population, the $2^{\text {nd }}, 3^{\text {rd }}$, and $4^{\text {th }}$ DMTAs were seen arising from the AA in $60 \%, 54 \%$, and $40 \%$ of the cases, ${ }^{3}$ respectively. Additionally, in the same Indian study, the $2^{\text {nd }}$ DMTA originated from the DPA in $10 \%$ of the feet, from the deep plantar arch in 18\% of the feet, and from the LTA in $10 \%$ of the feet. The $3^{\text {rd }}$ DMTA originated from the deep plantar arch in $16 \%$ of the feet, and from the LTA in $22 \%$ of feet. The $4^{\text {th }}$ DMTA originated from the deep plantar arch in $24 \%$ of the feet, and from the LTA in $18 \%$ of the feet. Another study on the Indian population also revealed that the $3^{\text {rd }}$ and $4^{\text {th }}$ DMTAs arose from the $2^{\text {nd }}$ DMTA in $5 \%$ of the cases. ${ }^{5}$

However, data on the $2^{\text {nd }}, 3^{\text {rd }}$ and $4^{\text {th }}$ DMTAs contrast slightly. Data from Australia (El Saeed et al) ${ }^{8}$ and India (Awari et al $)^{3}$ suggest that these DMTAs originated majorly from the AA. This is similar to data obtained in our setting, but specifically for the left feet. The origins of the $2^{\text {nd }}$ to $4^{\text {th }}$ DMTAs on the right feet, however, contrast sharply from all of the data that has been reported on it from other populations. Data on the origin of the DMTAs can help endovascular surgeons to select the artery to be revascularized based on the angiosome concept in critical limb ischemia cases to avoid the amputation of feet of diabetic patients, as well as in reconstructive surgeries. ${ }^{12,13}$ Therefore, in our setting, it is worth noting that approaches to the DMTA flaps should be slightly different when comparing procedures in the left feet with those in the right feet.

The DMTAs on the right feet were predominantly within the muscles, as compared with beneath or above. On the left feet, the $1^{\text {st }}$ DMTA was predominantly within the muscles, while the other DMTAs were mostly above the muscles. This data contrasts sharply with that of the Chinese population, ${ }^{7}$ in whom the first dorsal metatarsal artery lies superficial to the muscles in $11 \%$ of the population, and between the muscles and the $1^{\text {st }}$ metatarsal bone in $84 \%$. It has been documented that the flap selection is easy when the dorsal metatarsal artery is superficial, since, in this case, the dissection of the pedicle is easy. Therefore, in the present study, the left $2^{\text {nd }}, 3^{\text {rd }}$ and $4^{\text {th }}$ DMTAs would be more suitable for flap selection as compared with the other DMTAs.

The Dorsal Metatarsal artery has also been shown to portray variations in its relation to the dorsal interossei muscles. Data, especially on the $1^{\text {st }}$ DMTA from the Chinese population, showed that the vessel lies superficial to the muscle in $11 \%$ of the population, and between the muscle and the $1^{\text {st }}$ metatarsal bone in $84 \% .{ }^{6}$ However, in our case, we did not record any vessel that lay between the muscle fibers
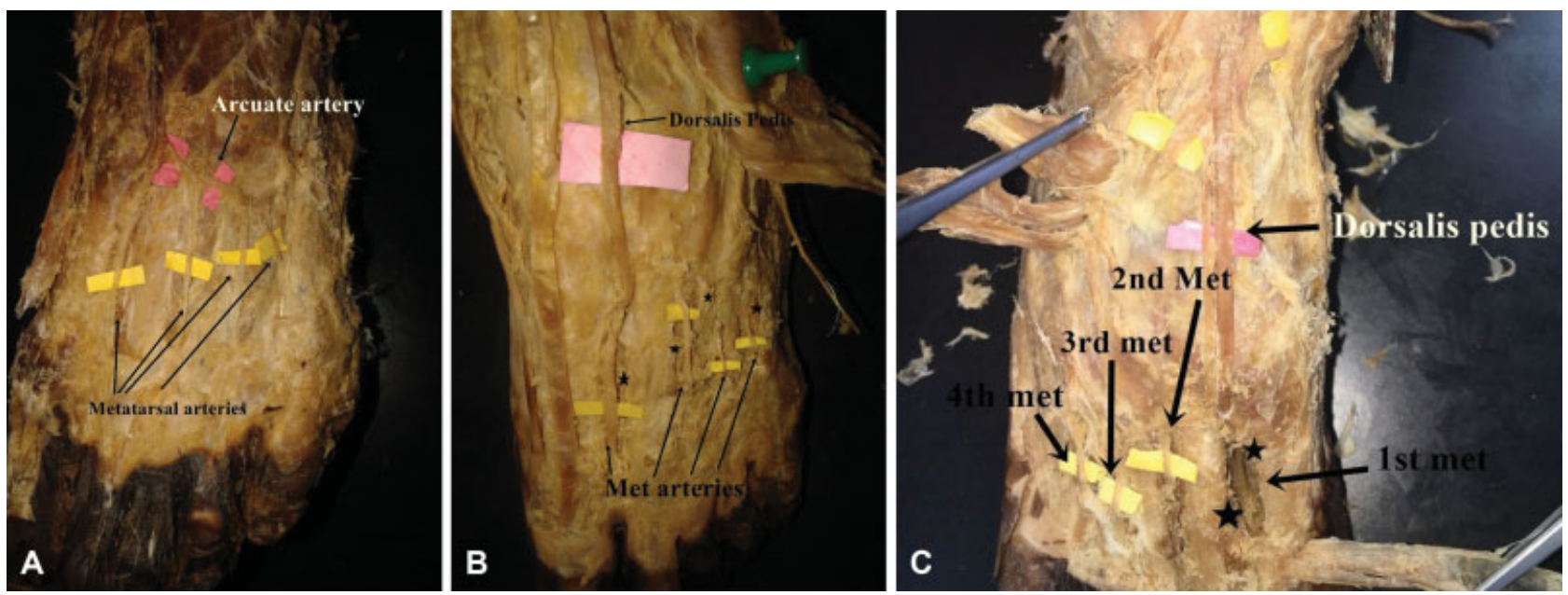

Fig. 4 (A) The dorsal metatarsal arteries are above the muscles. (B) The dorsal metatarsal arteries are within the dissected muscle fibers $\left({ }^{*}\right)$. (C) The $1^{\text {st }}$ dorsal metatarsal artery appears deep into the dissected muscle fibers $\left(^{*}\right)$. 
or beneath the muscles. When the vessel lies beneath or within the muscles, surgeons have been reported to cut open the muscles and try to dissect out the artery during flap selection. This causes many pitfalls during the surgery, by damaging the muscles, jeopardizing the blood supply to the skin, making the procedure more complicated, and prolonging the surgical time. ${ }^{6}$ This is in contrast to when the vessel is superficial, when the dissection of the pedicle is easy. The differences noted in the origin and in the course of the DMTAs may be due to the heterogeneity in the genetic makeup of different races. This difference may account for the different embryological development of the vessels and, therefore, in variant anatomy.

In conclusion, these results reveal that the DMTAs show variation in origin and in position in relation to the dorsal interossei muscles. These variations display bilateral asymmetry. Surgeons should be ware when taking flaps from the dorsum of the foot. Preoperative ultrasound evaluation is recommended.

\section{Conflicts of Interests}

The authors have no conflicts of interests to declare.

\section{Acknowledgments}

We are grateful to the staff of the gross anatomy laboratory for the technical assistance and to Ms. Antonina Odock for the typing the manuscript

\section{References}

1 Sinnatamby CS. 2011 Last's Anatomy. Regional and applied. 12th edition. Chapter 3. Churchill Livingstone, Elsevier: Lower limb; 145-146
2 Standring S. 2008 Gray's Anatomy. The anatomical basis of clinical practice. 40th edition. Section 9, chapter 84: Churchill Livingstone, Elsevier1455-1456

3 Awari PS, Vatsalaswamy P. Anatomical variations in dorsal metatarsal arteries with surgical significance: A cadaveric study. Indian J Vascular Endovascular Surgery 2017;4:176-179

4 Hou Z, Zou J, Wang Z, Zhong S. Anatomical classification of the first dorsal metatarsal artery and its clinical application. Plast Reconstr Surg 2013;132(06):1028e-1039e

5 Kulkarni V, Ramesh BR. A morphological study of dorsalis pedis artery and its clinical correlation. IOSR J Pharm Biol Sci 2012; 2:14-19

6 Upton J. Direct visualization of arterial anatomy during toe harvest dissections: clinical and radiological correlations. Plast Reconstr Surg 1998;102(06):1988-1992

7 Yeo CJ, Sebastin SJ, Ho SY, Tay SC, Puhaindran ME, Lim AY. The dorsal metatarsal artery perforator flap. Ann Plast Surg 2014;73 (04):441-444

8 El Saeed EM, El-Monsif AA, El-Sayed MA, Aly NM, Gezlan NA. Anatomical study of the dorsalis pedis artery and its surgical importance in reconstructive surgery. Alexandra Bull Fac Med 2008;44:557-571

9 Gabrielli C, Olave E. Origins of the dorsal metatarsal arteries in humans. Scand J Plast Reconstr Surg Hand Surg 2002;36(04): 221-225

10 Hollinshead WH. 1958Anatomy for Surgeons: The Back and Limbs. 3rd ed. Newyork: Hoeber- Harper; 1958

11 Atanasova M, Georgi P. Georgie and Jelev L., 2011. Intriguing variations of the tibial arteries and their clinical implications. IJAV 2011;4:45-47

12 Koul AR, Patil RK, Philip VK. Coverage of defects over toes with distally based local flaps: A report of four cases. Indian J Plast Surg 2008;41(01):62-66

13 Limthongthang R, Eamsobhana P. First dorsal metatarsal artery perforator flap to cover great toe defect. J Orthop Surg (Hong Kong) 2017;25(03):2309499017739497 